\title{
Proposed economic selection indices for the Simmentaler breed in South Africa
}

\author{
J.F. Kluyts, F.W.C. Neser ${ }^{\#}$ and M.J. Bradfield \\ Department of Animal Science, University of the Free State, P.O. Box 339, Bloemfontein 9300, South Africa
}

\begin{abstract}
The development of economic selection indices for an integrated Simmentaler production system was described. The breeding objective was defined in terms of production-, functional- and product quality traits. Criteria included in the total index were birth- and weaning weight (direct and maternal), final weight, mature cow weight, days-to-calving, backfat thickness, tenderness and marbling. The total merit index was termed as $\mathrm{I}_{\mathrm{T}}=-1.60 \mathrm{BW}_{\mathrm{D}}-1.95 \mathrm{BW}_{\mathrm{M}}+2.23 \mathrm{WW}_{\mathrm{D}}+1.75 \mathrm{WW}_{\mathrm{M}}-0.54 \mathrm{FW}-2.01 \mathrm{MCW}-13.21 \mathrm{CD}+$ 4.97 $\mathrm{BF}-2.36 \mathrm{~T}+12.66 \mathrm{M}$. The correlation between this index and the aggregate breeding objective was 0.988. The economic superiority of the progeny from the top $40 \%$ of animals selected on their ranking in the total index, relative to the average progeny, is expected to be R 119.51 .
\end{abstract}

Keywords: Beef cattle, breeding objectives, product quality, growth, functional traits

${ }^{\#}$ Corresponding author. E-Mail: neserfw.sci@mail.uovs.ac.za

\section{Introduction}

In practice, several or many traits influence an animal's value, although they do so in varying degrees (Hazel, 1943). Information on these traits can be combined in an index by a special use of Fisher's discriminant function, as proposed by Smith (1936) and Hazel (1943). The genetic gain attainable within a group of animals by selection for several traits simultaneously is the product of the selection differential, the correlation between the aggregate breeding value (breeding objective) and the selection index, and genetic variability. The greatest opportunity of enhancing the progress from selection is by ensuring that the correlation between the breeding objective and selection index is maximised. Hazel (1943) presented a multiple correlation method of constructing optimum selection indices. However, to solve the simultaneous equations the economic parameters (relative economic values), genetic parameters (heritability, genetic correlations) and phenotypic parameters (standard deviation, correlations) of/among traits must be known (Hazel, 1943). When these traits differ in variability, heritability, economic importance and in the correlation among their phenotypes and genotypes, index selection was more effective than independent culling levels or sequential selection (Hazel \& Lush, 1943; Young, 1961; Hazel et al., 1994).

A useful modification developed by C. R. Henderson was the separated application of the selection index in two steps (Hazel et al., 1994). The first step is the estimation of individual breeding values, through multitrait analysis, for each trait included in the definition of the aggregate breeding value. The second step is application of relative economic values. This separation has two important advantages. It permits use of the most complex and accurate Best Linear Unbiased Prediction (BLUP) techniques to estimate individual breeding values for each index trait, including adjustment for differing quantities of information. It then allows the economic values applied to vary with differing selection objectives, depending upon how different breeds are used in a breeding system or the particular production and marketing system, without recalculating breeding values. In this approach selection is based on a "genetic index" whereas a conventional selection index is based on the phenotype (Lin, 1990).

Formulas presented by Schneeberger et al. (1992) take account of the fact that traits in the objective can differ from the selection criteria used to predict the breeding values in the index, as well as the differences in the accuracy of prediction of individual breeding values. Breeding values predicted by multiple-trait animal model BLUP procedures can, therefore, be combined into an index to predict an aggregate breeding objective made up of economically important traits and their associated economic values (Schneeberger et al., 1992).

Although the theory of selection indices has been introduced into animal breeding more than 60 years ago and is highly developed in various forms, its application in practical breeding may not be very extensive. This is not due to constraints in selection index theory, but partly due to difficulties in the derivation of 
relative economic values as well as the paucity of information on the relationships among traits. Furthermore, optimal selection indices may not be extensively used since, in most genetic evaluations, not all measured traits are considered in the same multi-trait BLUP model, leading to difficulty in the construction of optimal selection indices. The method presented in this paper is indeed valid only under such a multitrait BLUP model.

Economic values have already been derived for economically important traits for the Simmentaler breed (Kluyts et al., 2007). Therefore, the objectives of this paper were (1) the construction of economic selection indices for the Simmentaler breed in South Africa and (2) to test the accuracy and efficiency of these indices, depending on which selection criteria are measured. It is important to note that traits included in the breeding objective were chosen on economic considerations while the choice of selection criteria depends on the cost, time and accuracy of the measurement. It was furthermore assumed that all traits were considered in a multi-trait BLUP model.

\section{Materials and Methods}

Henderson (1963), as quoted by Harris \& Newman (1994), noted that in Hazel's (1943) approach, optimum selection toward a breeding objective $\left(H=\sum \mathrm{a}_{\mathrm{i}} \mathrm{G}_{\mathrm{i}}\right)$ requires selection on an index (I) which correlates best with $\mathrm{H}$. In matrix notation the unrestricted index would be $\mathrm{I}=\mathbf{b}$ ' $\mathbf{X}$, where $\mathbf{X}$ is a $\mathrm{n} \times 1$ vector of sources of information and $\mathbf{b}$ is a $\mathrm{n} \times 1$ vector of weighing factors to be computed. The elements of $\mathbf{b}$ are chosen as to maximise genetic gain in a total (aggregate) breeding value or breeding objective. Where (a' $\mathbf{g}_{\mathbf{i}}$ ) is the aggregate measure of merit for individual $\mathrm{i}$, $\mathbf{a}$ is a $\mathrm{mx} 1$ vector of economic values (weights) and $\mathbf{g}$ is a $\mathrm{m} \times 1$ vector of breeding values (for animal i) for the traits in the breeding objective. Also, $\mathbf{a}=\mathbf{c} \mathbf{\prime} \mathbf{v}$, where $\mathbf{c}$ is a $\mathrm{m} \times 1$ vector of cumulative discounted expressions of $m$ breeding objective traits and $\mathbf{v}$ is a $\mathrm{m} \times 1$ vector with uncorrected economic values for the $m$ traits. The optimum set of selection index coefficients is those which maximise the correlation $\left(\mathrm{r}_{\mathrm{HI}}\right)$ or minimise the squared deviation between the selection index and the aggregate genotype (breeding objective) (Weller, 1994). Hazel (1943) showed that maximum $r_{\mathrm{HI}}$ is achieved when:

$$
\mathbf{P b}=\mathbf{G}_{12} \mathbf{a}
$$

Selection index weights are then calculated as:

$$
\mathbf{b}=\mathbf{P}^{-1} \mathbf{G}_{12} \mathbf{a}
$$

where $\mathbf{G}_{12}$ is a $\mathrm{n} \times \mathrm{m}$ genetic variance - covariance matrix for $\mathrm{m}$ traits affecting profitability and $\mathrm{n}$ correlated indicator traits (criteria) and incorporates the additive genetic relationships between sources of information; $\mathbf{P}$ is a $\mathrm{n} \times \mathrm{n}$ phenotypic (co)variance matrix of correlated indicator traits; and $\mathbf{a}$ is a $\mathrm{n} \times 1$ vector of relative economic values (Cunningham et al., 1970; James, 1982; Gibson \& Kennedy, 1990; Fewson, 1993; MacNiel et al., 1994).

Since selection is not directly based on phenotypic measures but on predicted breeding values and since multitrait solutions from BLUP consider environmental effects, the phenotypic variance-covariance matrix (P) is not needed for index construction (Lin, 1990). Although the phenotypic correlations have no effect on the derivation of index weights (coefficients) they are required for the calculations describing the index (Amer et al., 1998). The only information needed, in addition to the economic values, to allow prediction of the breeding objective, is information on the genetic variances and covariances among selection criteria in the index and on genetic covariances between the selection criteria and the objective traits (Schneeberger et al., 1992). If predicted breeding values instead of observed phenotypic measures are used in an index, solving for the index coefficients is by equation (3) (Schneeberger et al., 1992):

$$
\mathbf{b}=\mathbf{G}_{11}^{-1} \mathbf{G}_{12} \mathbf{a}
$$

where $\mathbf{b}$ is a vector of index weights (coefficients) for the predicted breeding values of the selection criteria (traits) in the index, $\mathbf{G}_{11}$ is the $\mathrm{n} \times \mathrm{n}$ genetic variance-covariance matrix of the $\mathrm{n}$ criteria in the index, $\mathbf{G}_{12}$ is the $\mathrm{n} \times \mathrm{m}$ genetic covariance matrix between the $\mathrm{n}$ selection criteria in the index and the $\mathrm{m}$ traits in the 
breeding objective and a is the vector of corrected economic values, expressed in South African Rand per unit of measurement, for the traits in the objective and, for this study, corrected with the discounted gene flow method described by McClintock \& Cunningham (1974).

The parameters for traits and criteria used in index construction are summarized in Table 1. These parameters were provided by Breedplan International for the South African Simmentaler breed as well as from literature reports (Koots et al., 1994a; Gregory et al., 1995a; b; Barwick \& Henzell, 1999; Meyer \& Johnston, 2001; Devitt et al., 2002; Martinez-Velazquez et al., 2003; Cundiff et al., 2004). Economic values were derived by Kluyts et al. (2007)

The economic value (Table 1) of a trait was defined by Hazel (1943) as the amount by which profit may be expected to change for each unit of improvement in the trait concerned, independent of effects from changes in other traits included in the definition of the breeding objective. Therefore, the economic value (a) of a given trait (i) was defined as the partial derivative $(\delta)$ of the profit equation $(\pi)$ with respect to the trait concerned whereby all traits $(\mathrm{x})$ are assumed to take their mean $(\mu)$ values:

$$
\mathrm{a}_{\mathrm{i}}=\delta \pi /\left.\delta \mathrm{x}_{\mathrm{i}}\right|_{\mathrm{x}=\mu}
$$

Table 1 Economic values (corrected with the DGF method) in Rand / unit (a), heritabilities $\left(\mathrm{h}^{2}\right)$, phenotypic $\left(\sigma_{\mathrm{P}}\right)$ and genetic $\left(\sigma_{\mathrm{A}}\right)$ standard deviations for the traits and criteria used in index construction

\begin{tabular}{lllrlcc}
\hline Trait & Symbol & unit & $\mathrm{a}$ & $\mathrm{h}^{2}$ & $\sigma_{\mathrm{P}}$ & $\sigma_{\mathrm{A}}$ \\
\hline Weaning weight -direct & $\mathrm{WW}_{\mathrm{D}}$ & $\mathrm{kg}$ & 2.12 & 0.21 & 26.49 & 12.04 \\
Weaning weight - maternal & $\mathrm{WW}_{\mathrm{M}}$ & $\mathrm{kg}$ & 1.69 & 0.12 & 26.49 & 9.0 \\
Final weight 600 days) & $\mathrm{FW}_{\mathrm{H}}$ & $\mathrm{kg}$ & -0.65 & 0.32 & 38.05 & 21.47 \\
Mature Cow weight & $\mathrm{MCW}$ & $\mathrm{kg}$ & -2.00 & 0.43 & 52.92 & 34.64 \\
Calving rate & $\mathrm{CR}$ & $\%$ & 13.27 & 0.17 & 3.47 & 1.43 \\
Days to calving & $\mathrm{CD}$ & $\mathrm{days}$ & -13.27 & 0.08 & 25.0 & 7.07 \\
Calving ease - direct & $\mathrm{CE}_{\mathrm{D}}$ & $\%$ & 1.48 & 0.13 & 2.02 & 0.73 \\
Calving ease - maternal & $\mathrm{CE}$ & $\%$ & 1.64 & 0.12 & 2.02 & 0.70 \\
Dressing percentage & $\mathrm{DP}$ & $\%$ & 17.16 & 0.39 & 1.9 & 1.19 \\
Backfat & $\mathrm{BF}$ & $\mathrm{mm}$ & 0.45 & 0.44 & 1.3 & 0.86 \\
Tenderness & $\mathrm{T}$ & $\mathrm{WBS} \mathrm{kg}$ & -5.03 & 0.29 & 1.3 & 0.70 \\
Marbling & $\mathrm{M}$ & $\mathrm{score}$ & 0.35 & 0.38 & 0.82 & 0.50 \\
& & & & & & \\
Criteria & & & & & & \\
Birth weight - direct & $\mathrm{BW}$ & $\mathrm{kg}$ & & 0.42 & 4.32 & 2.80 \\
Birth weight - maternal & $\mathrm{BW}$ & $\mathrm{kg}$ & & 0.08 & 4.32 & 1.23 \\
Scrotal circumference & $\mathrm{SC}$ & $\mathrm{cm}$ & & 0.36 & 2.70 & 1.62 \\
& & & & & & \\
\hline
\end{tabular}

The mean genetic correlations among traits provided by Breedplan International for the South African Simmentaler breed and synthesized from literature reports by Koots et al. (1994b), Graser et al. (1994), Nitter et al. (1994) and Johnston \& Bunter (1996) are summarized in Table 2.

Williams (1962a) labelled the Smith-Hazel index as an estimated index since the phenotypic and genetic parameters required for index construction are never known absolutely. The index has to be derived by use of sample estimates (Williams, 1962b). Sampling errors associated with estimation from a small data set could, therefore, affect the reliability of the index. Harris (1964) noted that, in practice, it was possible to detect some estimates that are not reasonable (impossible), i.e., where the estimates are outside the parameter space. Examples are (1) negative estimates of additive genetic variance, (2) estimates of the additive genetic variance that are greater than the estimates of phenotypic variance (heritability estimates greater than 1.0) and (3) estimates of the additive genetic correlation which are greater than 1.0 in absolute magnitude. Sales \& Hill (1976a; b) studied the effects of sampling errors on the efficiency of selection indices and concluded that the loss of efficiency is small even for estimates far from the correct value. Methods to improve the 
Table 2 Mean genetic correlations $\left(\mathrm{r}_{\mathrm{g}}\right)$ among 16 traits

\begin{tabular}{|c|c|c|c|c|c|c|c|c|c|c|c|c|c|c|c|}
\hline & $\mathrm{WW}_{\mathrm{M}}$ & YW & FW & MCW & CR & $\mathrm{CD}$ & $\mathrm{CE}_{\mathrm{D}}$ & $\mathrm{CE}_{\mathrm{M}}$ & DP & $\mathrm{BF}$ & $\mathrm{T}$ & $\mathrm{M}$ & $\mathrm{BW}_{\mathrm{D}}$ & $\mathrm{BW}_{\mathrm{M}}$ & $\mathrm{SC}$ \\
\hline $\mathrm{WW}_{\mathrm{D}}$ & -0.16 & 0.75 & 0.70 & 0.40 & - & - & -0.21 & - & - & -0.05 & - & - & 0.66 & -0.05 & 0.19 \\
\hline $\mathrm{WW}_{\mathrm{M}}$ & $*$ & - & - & - & - & - & - & - & - & - & - & - & -0.14 & 0.39 & 0.19 \\
\hline YW & & $*$ & 0.80 & 0.50 & - & - & -0.29 & - & - & -0.10 & - & - & 0.52 & - & 0.39 \\
\hline FW & & & $*$ & 0.75 & - & - & - & - & - & -0.15 & - & - & 0.55 & - & 0.15 \\
\hline MCW & & & & $*$ & - & - & -0.23 & - & - & -0.15 & - & - & 0.35 & - & 0.10 \\
\hline CR & & & & & $*$ & -0.97 & - & - & - & - & - & - & - & - & 0.63 \\
\hline $\mathrm{CD}$ & & & & & & $*$ & -0.10 & -0.20 & - & -0.20 & - & - & - & - & -0.20 \\
\hline$C E_{D}$ & & & & & & & $*$ & -0.30 & - & - & - & - & -0.74 & - & - \\
\hline $\mathrm{CE}_{\mathrm{M}}$ & & & & & & & & $*$ & - & - & - & - & - & -0.60 & - \\
\hline $\mathrm{DP}^{\mathrm{NI}}$ & & & & & & & & & $*$ & 0.30 & - & 0.25 & - & - & - \\
\hline $\mathrm{BF}$ & & & & & & & & & & $*$ & - & 0.24 & -0.27 & - & - \\
\hline $\mathrm{T}$ & & & & & & & & & & & $*$ & -0.31 & -0.01 & - & - \\
\hline M & & & & & & & & & & & & $*$ & 0.31 & - & - \\
\hline $\mathrm{BW}_{\mathrm{D}}$ & & & & & & & & & & & & & $*$ & -0.35 & 0.04 \\
\hline $\mathrm{BW}_{\mathrm{M}}$ & & & & & & & & & & & & & & $*$ & -0.07 \\
\hline
\end{tabular}

estimates of parameters to increase the efficiency of index selection were proposed by Hayes \& Hill (1980; 1981) and Tai (1989), while Tai (1986) proposed a method to construct a confidence interval for the expected response to multi-trait selection. Foulley \& Ollivier (1986) proposed a method to test the coherence of variance-covariance matrices. However, on a large data set, the genetic variance-covariance matrix among traits (i.e. variance-covariance matrix among genetic values of the traits) provides a reasonable estimate of the variance-covariance matrix among the estimated genetic values (Lin, 1990). With the use of a small data set, the variance-covariance matrix of true genetic values may be very different from the variancecovariance matrix of genetic estimates, thus affecting the efficiency of the derived index. According to Lin (1990) this is a problem associated with the use of a small data set rather than a problem of theoretical derivation.

Although it was assumed that parameters were estimated on a large data set, and the genetic variancecovariance matrix among genetic values of the traits will, therefore, provide a reasonable estimate of the variance-covariance matrix among the estimated genetic values, matrices were tested for coherence with the method of Foulley \& Ollivier (1986). According to Foulley \& Ollivier (1986) matrices will be coherent if:

- for any linear combination of selection objectives $\mathrm{H}=\mathrm{a}^{\prime} \mathrm{g}$, $\sigma_{\mathrm{H}}^{2}>0$

- $\quad$ and for any predictor $\mathrm{I}=\mathrm{a}^{\prime} \mathrm{g}$, $\sigma_{\mathrm{I}}^{2} / \sigma_{\mathrm{H}}^{2}=\lambda, \quad 0 \leq \lambda \leq 1$

Since the heritability of a trait is a ratio of variances $\left(h^{2}=\sigma_{A}^{2} / \sigma_{P}^{2}\right)$, variances are squared deviations, and a correlation between two variables is a simple function of the covariance of the variables and their standard deviations (Equation 6) (Bourdon, 1997), the variances and covariances to include in the matrices $\left(\mathbf{G}_{11}\right.$ and $\left.\mathbf{G}_{12}\right)$ were computed from the data in Tables 1 and 2 with the use of Equations 5 and 7.

$$
\begin{aligned}
& \sigma^{2}{ }_{A}=h^{2} \cdot \sigma_{P}^{2} \\
& r_{X, Y}=\operatorname{cov}(X, Y) / \sigma_{X} \sigma_{Y} \\
& \operatorname{cov}(X, Y)=r_{X, Y} \cdot \sigma_{X} \sigma_{Y}
\end{aligned}
$$

Where $r_{X, Y}=$ the genetic correlation between variables $X$ and $Y$; cov $(X, Y)=$ the covariance between variables $\mathrm{X}$ and $\mathrm{Y}$ and $\sigma_{\mathrm{X}}$ and $\sigma_{\mathrm{Y}}$ are the genetic standard deviations for $\mathrm{X}$ and $\mathrm{Y}$, respectively.

As stated above, the optimum set of selection index coefficients are those which maximise the correlation $\left(\mathrm{r}_{\mathrm{HI}}\right)$ or minimise the squared deviation between the selection index and the aggregate genotype 
(breeding objective). Therefore, according to Groen et al. (1994), the accuracy of index selection is a function of the correlation $\left(\mathrm{r}_{\mathrm{HI}}\right)$ between the aggregate genotype and the index and is calculated as:

$$
\mathrm{r}_{\mathrm{HI}}^{2}=\sigma_{\mathrm{I}}^{2} / \sigma_{\mathrm{H}}^{2}
$$

Where $\sigma_{\mathrm{I}}^{2}$ and $\sigma_{\mathrm{H}}^{2}$ are the variances of the index and the breeding objective respectively and since $\mathbf{P b}=\mathbf{G}_{12} \mathbf{a}$ (from Equation 1) it follows that these variances are:

$$
\begin{aligned}
& \sigma_{I}^{2}=\mathbf{b}^{\prime} \mathbf{P b}=\mathbf{b}^{\prime} \mathbf{G}_{12} \mathbf{a} \\
& \sigma_{\mathbf{H}}^{2}=\mathbf{a}^{\prime} \mathbf{G}_{22} \mathbf{a}
\end{aligned}
$$

Where $\mathbf{G}_{22}$ is the $\mathrm{mx} \mathrm{m}$ genetic variance-covariance matrix of the $\mathrm{m}$ traits in the breeding objective. Equation 9 is, however, only correct when assuming that fixed effects are known (Schneeberger et al., 1992).

According to Amer et al. (1998) responses $(\breve{\mathrm{R}})$ in each breeding objective trait (j) can be calculated using:

$$
\check{\mathrm{R}}_{\mathrm{j}}=\mathrm{i} \beta_{\mathrm{j} I} \sigma_{\mathrm{I}}=\mathrm{i}\left[\left(\mathbf{b}, \mathbf{G}_{12 \mathrm{j}}\right) / \sigma_{\mathrm{I}}\right]
$$

Where $i$ is the selection intensity, $\beta_{\mathrm{j}}$ is the genetic regression of the $\mathrm{j}^{\text {th }}$ recorded trait (criterion) on the index, $\mathbf{b}^{\prime}$ is a row vector of index coefficients, $\mathbf{G}_{12} \mathrm{j}$ is the $\mathrm{j}^{\text {th }}$ column of matrix $\mathbf{G}_{12}$ and $\sigma_{1}$ the standard deviation of the index which is the square root of the variance, $\mathbf{b}^{\prime} \mathbf{G}_{12} \mathbf{a}$ (from Equation 9$)$. Response in profit ( $\left(\check{R} \pi_{j}\right)$ due to genetic change in each trait (j) with selection intensity (i) can then be calculated as:

$$
\check{\mathrm{R}} \pi_{\mathrm{j}}=\check{\mathrm{R}}_{\mathrm{j}} \cdot \mathrm{a}_{\mathrm{j}}
$$

Where $a_{j}$ is the economic value of trait $j$.

Criteria (Table 1) to include in the index will be all the traits in the breeding objective except $\mathrm{CR}, \mathrm{SC}$, $\mathrm{CE}_{\mathrm{D}}, \mathrm{CE}_{\mathrm{M}}$ and $\mathrm{DP}$. Birth weight direct $\left(\mathrm{BW}_{\mathrm{D}}\right)$ and birth weight maternal $\left(\mathrm{BW}_{\mathrm{M}}\right)$ were included as criteria in the index. These criteria were chosen to assist in the prediction of calving ease.

The genetic variance-covariance matrix $\left(\mathbf{G}_{11}\right)$, with variances on diagonal and covariances offdiagonal, of the criteria $\left(\mathrm{WW}_{\mathrm{D}}, \mathrm{WW}_{\mathrm{M}}, \mathrm{FW}, \mathrm{MCW}, \mathrm{CD}, \mathrm{BF}, \mathrm{T}, \mathrm{M}, \mathrm{BW}_{\mathrm{D}}, \mathrm{BW}_{\mathrm{M}}\right)$ in the index as well as the genetic covariance matrix $\left(\mathbf{G}_{12}\right)$ between the selection criteria $\left(\mathrm{WW}_{\mathrm{D}}, \mathrm{WW}_{\mathrm{M}}, \mathrm{FW}, \mathrm{MCW}, \mathrm{CD}, \mathrm{BF}, \mathrm{T}, \mathrm{M}\right.$, $\left.\mathrm{BW}_{\mathrm{D}}, \mathrm{BW}_{\mathrm{M}}\right)$ in the index and the traits $\left(\mathrm{WW}_{\mathrm{D}}, \mathrm{WW}_{\mathrm{M}}, \mathrm{FW}, \mathrm{MCW}, \mathrm{CD}, \mathrm{CE}_{\mathrm{D}}, \mathrm{CE}_{\mathrm{M}}, \mathrm{DP}, \mathrm{BF}, \mathrm{T}, \mathrm{M}\right)$ in the breeding objective were then constructed.

Since there are a limited number of herds with breeding seasons where breeding values for $\mathrm{CD}$ can be derived, an alternative index $\left(\mathrm{I}_{\mathrm{A}}\right)$ was constructed that includes $\mathrm{SC}$ instead of $\mathrm{CD}$ as fertility criterion.

Since there are at present only a limited number of herds/animals with breeding values for scanned traits (backfat, tenderness and marbling) a primary index $\left(I_{P}\right)$ was developed with traits usually measured in a cow-calf production system (based on the results summarized in Table 3) to be used until more information on these scanned traits are available. This primary index includes only $\mathrm{WW}_{\mathrm{D}}, \mathrm{WW}_{\mathrm{M}}, \mathrm{MCW}$ and $\mathrm{CD}$ as criteria.

\section{Results and Discussion}

According to Kluyts et al. (2007) the breeding objective $\left(H=\sum a_{i} G_{i}\right)$ for the South African Simmentaler breed was defined as:

$$
\begin{aligned}
\mathrm{H}= & 2.12 \mathrm{WW}_{\mathrm{D}}+1.69 \mathrm{WW}_{\mathrm{M}}-0.65 \mathrm{FW}-2.00 \mathrm{MCW}-13.27 \mathrm{CD}+1.48 \mathrm{CE}_{\mathrm{D}}+1.64 \mathrm{CE}_{\mathrm{M}} \\
& +17.16 \mathrm{DP}+0.45 \mathrm{BF}-5.03 \mathrm{~T}+0.35 \mathrm{M}
\end{aligned}
$$

Therefore, let the vector of economic values be:

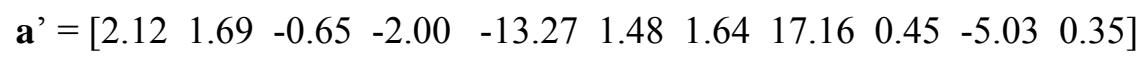


Matrices were tested with the method of Foulley \& Ollivier (1986) and they satisfy the criteria of coherence since $\sigma_{\mathrm{H}}^{2}=14639.61$ and $\lambda=0.9753$.

The vector of index coefficients (b) was then computed using Equation $3\left(\mathbf{b}=\mathbf{G}_{11}{ }^{-1} \mathbf{G}_{12} \mathbf{a}\right)$ as:

$\mathbf{b}_{\mathrm{T}}=\left[\begin{array}{llllllllll}2.23 & 1.75 & -0.54 & -2.01 & -13.21 & 4.97 & -2.36 & 12.66 & -1.60 & -1.95\end{array}\right]$

These index coefficients can now be multiplied with each EBV and summed to obtain the index value for an animal. Animals can then be ranked according to these index values and selection based on these rankings.

The total merit index $\left(\mathrm{I}_{\mathrm{T}}\right)$ for an integrated Simmentaler production system is:

$$
\begin{gathered}
\mathrm{I}_{\mathrm{T}}=-1.60 \mathrm{BW}_{\mathrm{D}}-1.95 \mathrm{BW}_{\mathrm{M}}+2.23 \mathrm{WW}_{\mathrm{D}}+1.75 \mathrm{WW}_{\mathrm{M}}-0.54 \mathrm{FW}-2.01 \mathrm{MCW} \\
-13.21 \mathrm{CD}+4.97 \mathrm{BF}-2.36 \mathrm{~T}+12.66 \mathrm{M}
\end{gathered}
$$

The variances of the index (equation 9) and breeding objective (equation 10) were calculated as 14278.18 and 14639.61 respectively. With Equation (8) the accuracy $\left(\mathrm{r}^{2} \mathrm{HI}\right)$ of the derived economic selection index, in predicting the breeding objective, was computed as 0.9753 . The correlation $\left(\mathrm{r}_{\mathrm{HI}}\right)$ between this index and the breeding objective is then 0.988 .

The alternative index $\left(\mathrm{I}_{\mathrm{A}}\right)$ (that includes $\mathrm{SC}$ and not $\mathrm{CD}$ as fertility criterion) for an integrated Simmentaler production system is:

$$
\begin{aligned}
\mathrm{I}_{\mathrm{A}}=12.53 \mathrm{BW}_{\mathrm{D}} & +13.18 \mathrm{BW}_{\mathrm{M}}-0.33 \mathrm{WW}_{\mathrm{D}}+0.46 \mathrm{WW}_{\mathrm{M}}-0.50 \mathrm{FW}-2.00 \mathrm{MCW} \\
& +15.90 \mathrm{SC}+43.69 \mathrm{BF}-11.69 \mathrm{~T}-31.89 \mathrm{M}
\end{aligned}
$$

The variance of the alternative index was 6640.149 . It was, however, only $45.4 \%$ accurate in predicting the breeding objective. The correlation $\left(\mathrm{r}_{\mathrm{HI}}\right)$ between this index and the breeding objective was only 0.674 .

To test the effect of individual criteria on the efficiency of the index $\left(\mathrm{I}_{\mathrm{T}}\right)$, these criteria were deleted one at a time from the index. The efficiency of these sub-indices was then compared to the efficiency of the

\begin{tabular}{|c|c|c|c|c|c|c|c|c|c|c|}
\hline \multirow[t]{2}{*}{$\mathrm{I}_{\mathrm{T}}$} & \multicolumn{10}{|c|}{ Criteria } \\
\hline & $\mathrm{WW}_{\mathrm{D}}$ & $\mathrm{WW}_{\mathrm{M}}$ & FW & MCW & $\mathrm{CD}$ & $\mathrm{BF}$ & $\mathrm{T}$ & M & $\mathrm{BW}_{\mathrm{D}}$ & $\mathrm{BW}_{\mathrm{M}}$ \\
\hline $\mathrm{r}_{\mathrm{HI}}^{2} \quad 0.9753$ & 0.9619 & 0.9623 & 0.9731 & 0.8412 & 0.4164 & 0.9748 & 0.9745 & 0.9741 & 0.9747 & 0.9745 \\
\hline Reduction & 0.013 & 0.013 & 0.002 & 0.134 & 0.559 & 0.001 & 0.001 & 0.001 & 0.001 & 0.001 \\
\hline
\end{tabular}
overall index. These results are summarized in Table 3.

Table 3 Reduction in accuracy of the sub-index, compared to the total index $\left(\mathrm{I}_{\mathrm{T}}\right)$, when individual criteria were dropped from the index

From Table 3 it is clear that most individual criteria have only a small influence on the efficiency of the index. However, when MCW or CD is dropped from the index the resultant sub-indices are only $84.1 \%$ or $41.6 \%$ accurate, respectively, compared to the $97.5 \%$ of the total index with these criteria included. Since dropping certain traits have a small influence on the efficiency of the index the possibility to construct the total index without these traits (criteria) was investigated. However, when criteria were dropped from the index the index weights (coefficients) of the remaining criteria changed. For instance when $\mathrm{WW}_{\mathrm{D}}$ was dropped from the index the index weights (b-values) for $\mathrm{BW}_{\mathrm{D}}$ and $\mathrm{BW}_{\mathrm{M}}$ changed from negative values to high positive values of 4.87 and 3.50, respectively. These values are even higher than the values assigned (in this sub-index) to $\mathrm{WW}_{\mathrm{M}}$ and $\mathrm{FW}$ of 1.26 and 0.08 respectively. Although these indices may be just as 
efficient economically as the total index it may be unacceptable because the positive weights assigned to birth weight may compromise $\mathrm{CE}_{\mathrm{D}}$ and $\mathrm{CE}_{\mathrm{M}}$. It was, therefore, decided to retain the total index.

Responses in each breeding objective trait were calculated using Equation (11) and the response in profit due to genetic change in each trait was then calculated with Equation (12). It was assumed that the selection intensity is equal to 1 . This can also be seen as the expected economic superiority, over the average progeny, of the progeny from the top $40 \%$ of animals selected on their ranking in the total index. Note that $\mathrm{i}$ is approximately equal to 1 when $40 \%$ of animals are selected $(i=0.966$; Falconer \& Mackay, 1996). These results are summarized in Table 4.

A primary index $\left(\mathrm{WW}_{\mathrm{D}}, \mathrm{WW}_{\mathrm{M}}, \mathrm{MCW}\right.$ and $\left.\mathrm{CD}\right)$ was constructed with the vector of index coefficients:

$$
\mathbf{b}_{\mathrm{P}}=\left[\begin{array}{llll}
1.54 & 1.57 & -2.23 & -13.33
\end{array}\right]
$$

The variance $\left(\sigma_{I}^{2}\right)$ of this index $\left(I_{P}\right)$ was computed at 14161.95 . The accuracy of $I_{P}$ is $96.74 \%$ and correlation with the objective 0.984 . The expected responses when selection is based on this index are also summarized in Table 4.

From Table 4 it can be seen that, with selection on $\mathrm{I}_{\mathrm{T}}$, all the traits changed in the desired direction except $\mathrm{WW}_{\mathrm{D}}$ and made a positive contribution to profit. The largest contribution came from the functional traits (fertility) and mature-cow-weight. Ponzoni \& Newman (1989) also concluded that, under most circumstances the trait making the greatest positive contribution to genetic gain in economic units was calving day $(\mathrm{CD})$. $\mathrm{WW}_{\mathrm{D}}$, on the other hand, will be reduced with 1.48 units $(\mathrm{kg})$. The main reason for this decrease is the relative high genetic correlation between $\mathrm{WW}_{\mathrm{D}}$ and $\mathrm{MCW}\left(\mathrm{r}_{\mathrm{G}}=0.4\right)$ and the relatively high negative economic value of MCW. In their study, Nitter et al. (1994) showed positive economic responses for growth and reproduction whereas the economic response in carcass value, maintenance and calving difficulty were negative. When selection is based on $\mathrm{I}_{\mathrm{P}}$ the expected response in total profit will be almost the same as with selection on $\mathrm{I}_{\mathrm{T}}$. There are, however, no changes expected in the quality traits (dressing percentage, marbling and tenderness) with selection on $\mathrm{I}_{\mathrm{P}}$. The alternative index is clearly the least efficient economically. With $\mathrm{I}_{\mathrm{A}}$ relatively more emphasis is placed on weight traits $\left(\mathrm{BW}_{\mathrm{D}}\right.$ and $\left.\mathrm{BW}_{\mathrm{M}}\right)$ than on fertility traits as compared with the other indices. These heavier weights placed on early growth resulted in a reduction in calving ease (direct and maternal). It is furthermore concluded that CD cannot be excluded from the index. It is also clear from these results that, the higher the variance of the index the greater is the expected economic response when selection is based on that specific index.

Table 4 Properties of indices, expected responses ( $\breve{\mathrm{R}})$ in traits (per unit) and expected economic superiority or expected response in profit ( $\breve{R} \pi$ in Rand) of the progeny from animals selected on different indices $\left(\mathrm{I}_{\mathrm{T}}=\right.$ total index, $\mathrm{I}_{\mathrm{A}}=$ alternative index and $\mathrm{I}_{\mathrm{P}}=$ primary index $)$

\begin{tabular}{|c|c|c|c|c|c|c|}
\hline $\begin{array}{l}\text { Index } \\
\text { Trait }\end{array}$ & $\check{\mathrm{R}}$ & $\check{\mathrm{R}} \pi$ & $\check{\mathrm{R}}$ & $\check{\mathrm{R}} \pi$ & $\check{\mathrm{R}}$ & $\check{\mathrm{R}} \pi$ \\
\hline $\mathrm{WW}_{\mathrm{D}}$ & -1.48 & -3.138 & -2.143 & -4.543 & -1.479 & -3.136 \\
\hline $\mathrm{WW}_{\mathrm{M}}$ & 0.84 & 1.42 & 1.224 & 2.069 & 0.844 & 1.426 \\
\hline $\mathrm{FW}$ & -8.647 & 5.62 & -12.634 & 8.212 & -8.111 & 5.272 \\
\hline MCW & -20.232 & 40.464 & -29.629 & 59.258 & -20.327 & 40.654 \\
\hline CD & -5.577 & 74.007 & -1.099 & 14.583 & -5.599 & 74.299 \\
\hline $\mathrm{CE}_{\mathrm{D}}$ & 0.141 & 0.209 & -0.082 & -0.122 & 0.143 & 0.212 \\
\hline $\mathrm{CE}_{\mathrm{M}}$ & 0.118 & 0.194 & -0.084 & -0.137 & 0.111 & 0.182 \\
\hline DP & 0.029 & 0.498 & 0.106 & 0.819 & 0 & 0 \\
\hline $\mathrm{BF}$ & 0.263 & 0.118 & 0.385 & 0.173 & 0.214 & 0.096 \\
\hline $\mathrm{T}$ & -0.021 & 0.106 & -0.031 & 0.156 & 0 & 0 \\
\hline M & 0.027 & 0.010 & 0.040 & 0.014 & 0 & 0 \\
\hline Accuracy (\%) & \multicolumn{2}{|c|}{97.53} & \multicolumn{2}{|c|}{45.40} & \multicolumn{2}{|c|}{96.74} \\
\hline $\mathrm{r}_{\mathrm{HI}}$ & \multicolumn{2}{|c|}{0.988} & \multicolumn{2}{|c|}{0.674} & \multicolumn{2}{|c|}{0.984} \\
\hline Total (R) & & 119.51 & & 81.48 & & 119.01 \\
\hline
\end{tabular}




\section{Conclusions}

The primary index constructed in this study is not the same as a sub-index. Sub-indices can be constructed for sub-systems (e.g. cow-calf system) of the integrated system, by setting the economic values of certain traits to zero (Amer et al., 1998). The primary index is defined for the total breeding objective of an integrated system but include only criteria usually measured in a cow-calf production system. The intention is that this index is to be used as a first index until more information, especially on scanned (product quality) traits, becomes available.

Many of the properties and constraints of these indices are related to a pure-breeding situation, and may not be the case when modelling a scenario involving a terminal or maternal crossbreeding situation.

In this article a detailed description of the development of an economic selection index was presented. Although these indices were developed specifically for the Simmentaler breed in South Africa, the methods employed can be used to develop indices for different breeds and/or different production systems within the same breed. Only small changes in the economic values, definition of the breeding objective, and correlation structure between traits and criteria are necessary.

Application of these principles and results is necessary if the beef cattle industry is to maximise the exploitation of genetics and to improve its relative competitive position. This approach may have wide ranging benefits, not only for the beef cattle industry, but also for consumers.

\section{Acknowledgements}

The NRF provided financial support for this study. The Simmentaler Cattle Breeders' Society of Southern Africa and Breedplan International provided data and information used in this study.

\section{References}

Amer, P.R., Crump, R. \& Simm, G., 1998. A terminal sire selection index for UK beef cattle. Anim. Sci. 67, 445-454.

Barwick, S.A. \& Henzell, A.L., 1999. Assessing the value of improved marbling in beef breeding objectives and selection. Aust. J. Agric. Res. 50, 503-512.

Bourdon, R.M., 1997. Understanding Animal Breeding. Prentice-Hall, Inc., New Jersey.

Cundiff, L.V., Wheeler, T.L., Gregory, K.E., Shackelford, S.D., Koohmaraie, M., Thallman, R.M., Snowder, G.D. \& Van Vleck, L.D., 2004. Preliminary results from Cycle VII of the cattle germplasm evaluation program at the Roman L. Hruska U.S. meat animal research centre. Progress Report No. 22. www.marc.usda.gov/cattle/gpe/GPE22.pdf

Cunningham, E.P., Moen, R.A. \& Gjedrem, T., 1970. Restriction of selection indexes. Biometrics 26, 67-74. Devitt, C.J.B., Wilton, J.W., Mandell, I.B., Fernandes, T.L. \& Miller, S.P., 2002. Genetic evaluation of tenderness in the longissimus in multi-breed populations of beef cattle and the implications of selection. In: Proc. $7^{\text {th }}$ Wrld. Cong. Genet. Appl. Livest. Prod., Montpellier (France).

Falconer, D.S. \& Mackay, T.F.C., 1996. Introduction to Quantitative Genetics. Prentice-Hall, London.

Fewson, D., 1993. Definition of the breeding objective. In: Design of Livestock Breeding Programs. Anim. Genet. Breed. Unit, Univ. New England, Armidale, NSW.

Foulley, J.L. \& Ollivier, L., 1986. A note on the criteria of coherence for the parameters used in index construction. J. Anim. Breed. Genet. 103, 81-86.

Gibson, J.P. \& Kennedy, B.W., 1990. The use of constrained selection indexes in breeding for economic merit. Theor. Appl. Genet. 80, 801-805.

Graser, H-U., Nitter, G. \& Barwick, S.A., 1994. Evaluation of advanced industry breeding schemes for Australian beef cattle. 2. Selection on combinations of growth, reproduction and carcass traits. Aust. J. Agric. Res. 45, 1641-1656.

Gregory, K.E., Cundiff, L.V. \& Koch, R.M., 1995a. Genetic and phenotypic (co)variances for production traits of female populations of purebred and composite beef cattle. J. Anim. Sci. 73, 2235-2242.

Gregory, K.E., Cundiff, L.V. \& Koch, R.M., 1995b. Genetic and phenotypic (co)variances for growth and carcass traits of purebred and composite populations of beef cattle. J. Anim. Sci. 73, 1920-1926.

Groen, A.F., Meuwissen, T.H.E., Vollema, A.R. \& Brascamp, E.W., 1994. A comparison of alternative index procedures for multiple generation selection on non-linear profit. Anim. Prod. 59, 1-9. 
Harris, D.L., 1964. Expected and predicted progress from index selection involving estimates of population parameters. Biometrics 20, 46-72.

Harris, D.L. \& Newman, S., 1994. Breeding for profit: Synergism between genetic improvement and livestock production. A Review. J. Anim. Sci. 72, 2178-2200.

Hayes, J.F. \& Hill, W.G., 1980. A reparameterization of a genetic selection index to locate its sampling properties. Biometrics 36, 237-248.

Hayes, J.F. \& Hill, W.G., 1981. Modification of estimates of parameters in construction of genetic selection indices ('Bending'). Biometrics 37, 483-493.

Hazel, L.N., 1943. The genetic basis for constructing selection indexes. Genetics 28, 476-490.

Hazel, L.N. \& Lush, J.L., 1943. The efficiency of three methods of selection. J. Hered. 33, 393-399.

Hazel, L.N., Dickerson, G.E. \& Freeman, A.E., 1994. Symposium: Selection index theory. The selection index - Then, now and for the future. J. Dairy Sci. 77, 3236-3251.

James, J.W., 1982. Construction, uses, and problems of multitrait selection indices. In: Proc. $2^{\text {nd }}$ Wrld. Cong. Genet. Appl. Livest. Prod. Madrid (Spain).

Johnston, D.J. \& Bunter, K.L., 1996. Days to calving in Angus cattle: Genetic and environmental effects, and covariances with other traits. Livest. Prod. Sci. 45, 13-22.

Kluyts, J.F., Neser, F.W.C. \& Bradfield, M.J., 2007. Derivation of economic values for the Simmentaler breed in South Africa. S. Afr. J. Anim. Sci. 37, 107-121.

Koots, K.R., Gibson, J.P., Smith, C. \& Wilton, J.W., 1994a. Analysis of published genetic parameter estimates for beef production traits. 1. Heritability. Anim. Breed. Abstr. 62, 309-338.

Koots, K.R., Gibson, J.P. \& Wilton, J.W., 1994b. Analysis of published genetic parameter estimates for beef production traits. 2. Phenotypic and genetic correlations. Anim. Breed. Abstr. 62, 825-853.

Lin, C.Y., 1990. A unified procedure of computing restricted best linear unbiased prediction and restricted selection index. J. Anim. Breed. Genet. 107, 311-315.

MacNiel, M.D., Newman, S., Enns, R.M. \& Stewart-Smith, J., 1994. Relative economic values for Canadian beef production using specialized sire and dam lines. Can. J. Anim. Sci. 74, 411-417.

Martinez-Velazquez, G., Gregory, K.E., Bennett, G.L. \& Van Vleck, L.D., 2003. Genetic relationships between scrotal circumference and female reproductive traits. J. Anim. Sci. 81, 395-401.

McClintock, A.E. \& Cunningham, E.P., 1974. Selection in dual purpose cattle populations: defining the breeding objective. Anim. Prod. 18, 237-247.

Meyer, K. \& Johnston, D.J., 2001. Estimates of genetic parameters from random regression analysis of scrotal circumference and days to calving. In: Proc. $14^{\text {th }}$ Conf. Assoc. Advmt. Anim. Breed. Genet. Queenstown (New Zealand).

Nitter, G., Graser, H-U. \& Barwick, S.A., 1994. Evaluation of advanced industry breeding schemes for Australian beef cattle. 1. Method of evaluation and analysis for an example population structure. Aust. J. Agric. Res. 45, 1641-1656.

Ponzoni, R.W. \& Newman, S., 1989. Developing breeding objectives for Australian beef cattle breeding. Anim. Prod. 49, 35-47.

Sales, J. \& Hill, W.G., 1976a. Effect of sampling errors on efficiency of selection indices. 1. Use of information from relatives for single trait improvement. Anim. Prod. 22, 1-17.

Sales, J. \& Hill, W.G., 1976b. Effect of sampling errors on efficiency of selection indices. 1. Use of information on associated traits for improvement of a single trait. Anim. Prod. 23, 1-14.

Schneeberger, M., Barwick, S.A., Crow, G.H. \& Hammond, K., 1992. Economic indices using breeding values predicted by BLUP. J. Anim. Breed. Genet. 109, 180-187.

Smith, H.F., 1936. A discriminant function for plant selection. Ann. Eugenics 7, 240-250.

Tai, G.C.C., 1986. A method to construct confidence interval for expected response to multi-trait selection. Theor. Appl. Genet. 71, 595-599.

Tai, G.C.C., 1989. A proposal to improve the efficiency of index selection by 'rounding'. Theor. Appl. Genet. 78, 798-800.

Weller, J.I., 1994. Economic Aspects of Animal Breeding. Chapman \& Hall, London.

Williams, J.S., 1962a. The evaluation of a selection index. Biometrics 18, 375-393.

Williams, J.S., 1962b. Some statistical properties of a genetic selection index. Biometrika 49, 325-337. 
Young, S.S.Y., 1961. A further examination of the relative efficiency of three methods of selection for genetic gains under less restricted conditions. Genet Res. 2, 106-121.

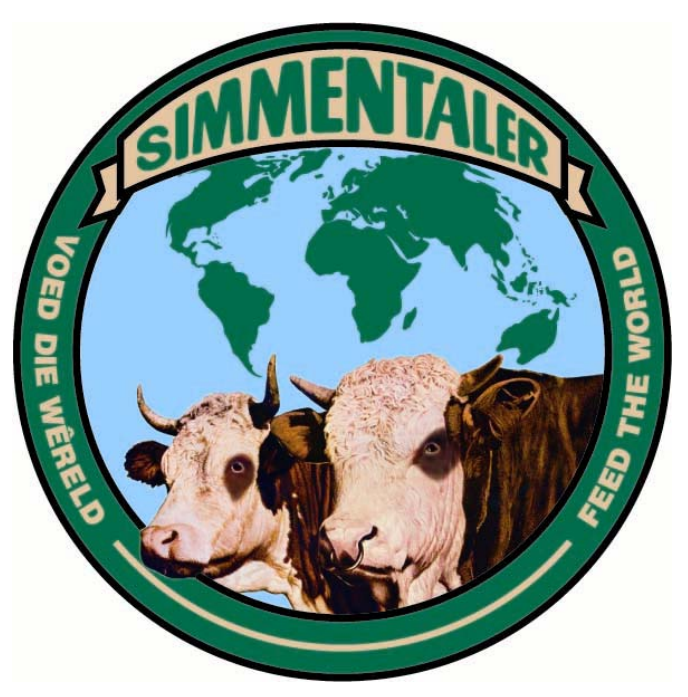

www.simmentaler.org

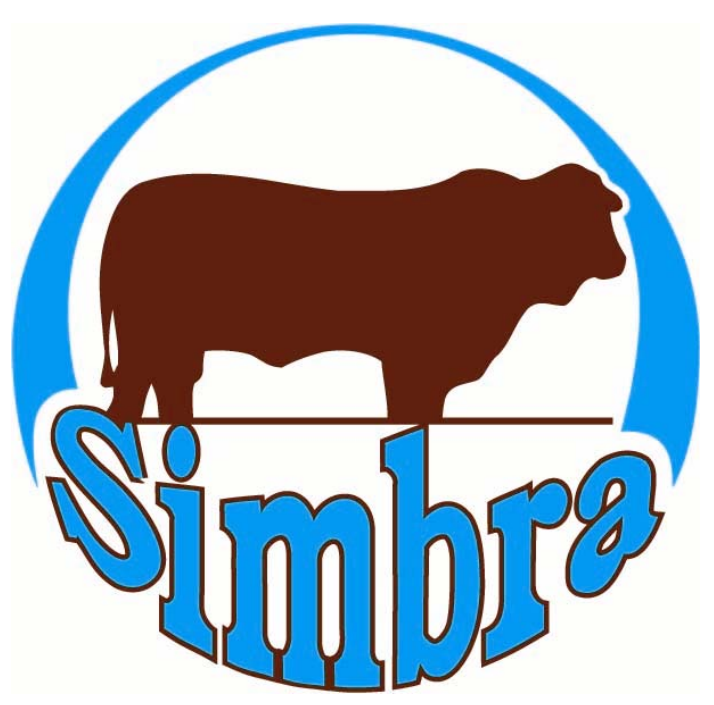

wWw.simbra.org 